\title{
Feminist-Cognitive-Behavioral and Process-Psychodynamic Treatments for Men Who Batter: Interaction of Abuser Traits and Treatment Models
}

\author{
Daniel G. Saunders \\ University of Michigan
}

\begin{abstract}
At a community-based domestic violence program, 218 men with a history of partner abuse were randomly assigned to either feminist-cognitive-behavioral or processpsychodynamic group treatments. The treatments were not hypothesized to differ in outcome. However, men with particular characteristics were expected to have lower recidivism rates depending on the type of treatment received. Treatment integrity was verified through audio-taped codings of each session. The partners of $79 \%$ of the 136 treatment completers gave reports of the men's behavior an average of 2 years posttreatment. These reports were supplemented with arrest records and self-reports. Rates of violence did not differ significantly between the two types of treatment nor did reports from the women of their fear level, general changes perceived in the men, and conflict resolution methods. However, interaction effects were found between some offender traits and the two treatments. As predicted, men with dependent personalities had better outcomes in the process-psychodynamic groups and those with antisocial traits had better outcomes in the cognitive-behavioral groups. The results suggest that more effective treatment may occur if it is tailored to specific characteristics of offenders.
\end{abstract}

Since the 1970s treatment programs for men who batter have proliferated, but tests of their effectiveness have not kept pace. Evaluations rarely include adequate comparison or control groups. For example, of the 26 studies reviewed by Hamberger and Hastings (1993) and Tolman and Edleson (1992), only 7 had comparison groups and only one of them had a true experimental design. Moreover, the posttreatment follow-up periods have generally been brief and do not always rely an reports from the men's partners, which are the most reliable sources of information. These studies and the problems with their methods have been carefully reviewed elsewhere (Hamberger \& Hastings, 1993; Holtworth-Munroe, Beatty, \& Anglin, 1995; Rosenfeld, 1992; Tolman \& Edleson, 1995; Saunders \& Azar, 1989).

The most commonly evaluated method is cognitive-behavioral, primarily in a men's group format and usually combined with gender role resocialization and methods to reduce male dominance. Only one study could be founded which experimentally 
compared this approach with another approach. Edleson and Syers $(1990,1991)$ compared: (1) a minimally structured self-help model with a peer facilitator and professional consultant, (2) a structured educational model (cognitive-behavioral) with regular readings and assignments, and (3) a combined model that presented material in less detail than the educational model and allowed more time for work on individual problems. Reports from $52 \%$ of the partners, or $8 \%$ of the men 6 months after treatment, nonsignificantly favored the education and combined groups. At 18 months posttreatment, reports from $46 \%$ of the women or the men showed even less difference among treatment approaches. Other studies used quasi-experimental designs or had small samples (e.g. Dutton, 1986; Harrell, 1990; Stosny).

In the study reported here, I attempted to improve on previous evaluations by obtaining a higher rate of response during follow-up and by ensuring that the treatments were applied according to their stated goals. The study also tested more theoretically distinct treatment models than the Edleson and Syers comparison. Risk factor research on domestic violence, which supports a number of theoretical explanations for domestic violence (Van Hasselt, Morrison, Bellak, \& Hersen, 1988) suggested two different approaches for comparison. This research consistently shows that boys who witness violence between their parents or who are abused themselves are more likely to be spouse abusers when they grow up (Hotaling \& Sugarman, 1986). Psychological abuse of boys by their parents also seems to be a risk factor (Dutton, van Ginkel, \& Starzomski, 1995). However, different theories can be used to explain the intergenerational transmission of violence. Recent reviews of the research include genetic, social learning, and attachment theories (Holtzworth-Munroe \& Stuart, 1994).

Principles of social learning theory, such as imitation and modeling, are frequently offered to explain the transmission (O'Leary, 1988). In addition, the lack of adequate role models means that interpersonal skills will be lacking in these men and there is evidence that they have such skill deficits (reviewed in Holtzworth-Munroe, 1992; Tolman \& Bennett, 1990). They may also learn cognitive distortions from their fathers or have trauma-induced beliefs about themselves that lead to cognitive distortions. Thus cognitive therapies are often used with these men. These individual level explanations of learning are often combined with sociocultural explanations. Some feminist theories, for example, maintain that these individual factors will most likely lead to violence in cultures that support violence against women. There is evidence from cross-cultural studies that patriarchal norms and structures are risk factors for abuse (Levenson, 1989; Yllo, 1984). Many treatment programs integrate behavioral, cognitive, and feminist theories in their treatment approaches (e.g., Ganley, 1989) and one of the models tested here was such a combined Feminist-Cognitive-Behavioral Treatment (FEBT) approach. It was developed over a number of years and is typical of many programs throughout the country (e.g., Edleson, 1984; Saunders, 1984). It combined skillstraining and gender role resocialization in a highly structured format. Brief lectures, demonstration role-plays, behavioral rehearsal, and homework assignments were the primary methods. More details about treatment methods are presented in the Method section. This model assumed that the violence is caused by: (1) behavioral skills deficits that reduce men's ability to state needs and feelings directly, thus repressing anger or leading to its immediate expression; (2) cognitive skills deficits that generate anger and/or rationalizations internally through cognitive distortions and negative self-talk; and (3) cultural norms and structures that support male dominance and fail to punish woman abuse.

The risk factor research can also support a psychodynamic perspective. The childhood abuse commonly witnessed or experienced by these men can have several outcomes with psychodynamic explanations. The explanations center on attempts to resolve childhood trau- 
mas and subsequent development of various attachment disorders. This theoretical model assumes that the men will identify with the aggressor in order to feel more powerful, perpetrate the same trauma onto others in order to gain a sense of control over the trauma, and/or defend against painful memories through anger and aggression. There is growing evidence that many of these men develop PTSD symptoms related to childhood trauma (Dutton, 1995) and a variety of personality disorders, including borderline/schizoidal, antisocial/narcissistic, and passive-dependent/compulsive disorders (Hamberger \& Hastings, 1986). Psychodynamic theories can also be placed in a cultural context, in particular the impact of patriarchy on male socialization and the channeling of vulnerable feelings into anger (Scher \& Stevens, 1987).

The psychodynamic interpretation of the risk factor research led to the development of a Process-Psychodynamic Treatment (PPT) model. It was much less structured than the FCBT model because it assumed that the most effective learning occurs through the process of supportive, nondidactic group relationships (Jennings, 1987). The model assumed that violence was caused primarily by childhood traumas experienced by the men (e.g., witnessing abuse of a loved one and/or being abused) and that the latter displace anger about these traumas is displaced onto adult relationships. The leaders of this approach try to create a supportive environment in which the men can reexperience childhood traumas, grieve their losses, give up control over others, and learn to empathize with others (Whitfield, 1987). "Insight" models of this type have been criticized for failing to confront the violence directly and overemphasizing support and empathy, which may reinforce abusers' rationalizations; insight approaches may also take too long to work (Adams, 1988). Such reservations about unstructured, insight models led to the development of feminist-cognitive-behavioral models (Saunders, 1984), yet we believed that all models needed to be empirically tested.

One purpose of this study was to test the relative effectiveness of these two models for preventing the recurrence of men's violence against their partners. Although cognitivebehavioral methods had been evaluated previously, process-psychodynamic methods had not been. Neither treatment was predicted to be superior on the main outcome measure: the partners' reports of the abusers' behavior after treatment. Comparisons of cognitivebehavioral and insight approaches often find no differences on major outcome variables. For example, Deffenbacher and his colleagues (Deffenbacher, McNamara, Stark, \& Sabadell, 1990) found no differences between cognitive-relaxation treatment and a process-oriented approach to anger management in a well-controlled study with college students.

Another purpose of the study was to test the proposition that offenders with particular traits would have better outcomes depending on the type of treatment they received. Studies of rehabilitation programs for offenders of all types show poor results unless they are matched with appropriate treatments. One meta-analysis (Andrews et al., 1990) showed that positive outcomes only occur when the styles and modes of treatment are matched with client needs and styles of learning.

Competing theories about domestic violence may be reconciled at least in part through evidence of different types of abusers. Abusers can be differentiated along a number of variables, including the extent of childhood victimization, type of personality disorder, and attitudes about women. Three types generally emerge (Holtzworth-Munroe \& Stuart, 1994): (1) Men who experienced the most severe childhood physical abuse tend to develop antisocial traits including generalized aggression, substance abuse, and proviolence norms. They show little or no remorse, have the most rigid views of gender roles, and can be theorized to have a dismissing attachment style. (2) Men who experienced the most severe 
parental rejection appear to develop borderline traits (Dutton \& Starzomski, 1993) and tend to be the most emotionally abusive, are emotionally volatile, and have the highest dependency needs. They probably have preoccupied or ambivalent attachment styles. (3) Men who experienced the least amount of childhood trauma tend to be compulsive and lacking in communication skills. They have low to moderate dependency needs and may have secure or preoccupied attachment styles.

The feminist-cognitive-behavioral model seems best suited to men with antisocial traits. Although they were most severely abused as children, they are not likely to be aware of the need to resolve their traumas and are unlikely to respond well to relationship-based, insight approaches. They probably need the most work on skills-training and attitude change. The process-psychodynamic model seems best suited for men with moderate to high levels of dependency needs because they are much more likely to engage in group process and methods for enhancing self-awareness. Therefore, in this study, it was predicted that the more dependent the personality, the more likely there would be better outcomes in the process psychodynamic group. Conversely, the more antisocial the personality, the more likely there would be better outcomes in the feminist-cognitive-behavioral group. Outcome was based on the partners' reports of abuse, conflict-resolution method, fear, and general changes in the men many months after they ended treatment.

\section{METHOD}

\section{Sample}

Men. Those who agreed to participate in the experiment $(n=218)$ were recruited from men who had been assessed and accepted for treatment at a family counseling agency that was certified as an outpatient mental health clinic. Most of the men had been referred by a deferred prosecution program (17\%) or probation department following prosecution (59\%). The others were referred by social service agencies, attorneys, friends, family members, or themselves. The average age of the men was $32.4(S D=8.3)$. Fourteen percent were AfricanAmerican, 3\% were Hispanic, $4 \%$ Native American, $1 \%$ Asian, and the remainder were Euro-American ( $78 \%)$. Their average income was $\$ 13,435$ per year $(S D=\$ 10,162)$. All but $18 \%$ of the men had graduated from high school, with $23 \%$ having some college, $11 \%$ having college degrees, and $2 \%$ having attended graduate school. Their average years of education was $12.6(S D=1.9)$. Men who completed treatment $(n=136)$, who are the focus of this report, were more likely to be Euro-American $(84 \%)$, to have higher incomes $(\$ 14,540)$, and to have more years of education (13.0). During an intake interview, 53\% of the men reported being punished by a parent more severely than the use of a slap or spanking. Almost half $(43 \%)$ reported verbal abuse from a parent.

Women. Attempts were made to contact all of the partners of the men who completed the assessment phase and agreed to participate in the experiment (procedures described below). Of the 218 men assigned to a treatment condition, 199 of the partners could be located and they were contacted. There were several purposes for these contacts: (1) to inquire about their willingness to participate in pretreatment and posttreatment interviews; (2) to inform them of the emergency, counseling and legal services available to them in the community; (3) to explain what might occur while their partners were in treatment and of the need not to view their partners' treatment as a panacea; and (4) to initiate a safety plan if needed. Pretreatment interviews were designed to last 30 to 45 minutes and posttreat- 
ment interviews were designed to last 10 to 20 minutes. The women were given a choice of telephone or in-person interviews or of answering a mailed questionnaire. Procedures similar to those used by other researchers (Parker \& Ulrich, 1990) were developed and implemented to protect the safety of the women and the interviewer regardless of the data collection method. The original design called for data collection at the assessment phase, the beginning of treatment, half-way through treatment, and 3,6,9,12, and 18 months after treatment. The focus was shifted to 18 -month follow-ups and beyond because of initial difficulties in locating women and because of evidence that many men are likely to be violent beyond the first 6-month follow-up phase (Dunford, 1992).

The interviews covered psychological and physical abuse, level of fear, general changes in the men, and conflict resolution methods (described later). The women were asked about any incidents of abuse since the end of treatment or since their last posttreatment interview. In the initial interview we also obtained the names and telephone numbers of friends and relatives likely to know their whereabouts during the follow-up phase. The women were paid between $\$ 10$ and $\$ 30$ for each interview, depending on its length and time since treatment. These and other methods of locating battered women and providing incentives for participation had been used successfully by other researchers (Rumptz, Sullivan, Davidson, \& Basta, 1991). To increase response rates during long-term followup of 18 months and beyond, a short version of the questionnaire was offered (described below).

Of the men who completed treatment $(n=136), 79 \%$ of their partners were located and agreed to participate during the follow-up period $(86 \%(n=55)$ in the FCBT condition and $72 \%(n=52)$ in the PPT condition). About half of the women provided information once (46\%), but a large proportion (42\%) provided information 4 to 6 times $(41 \%, \mathrm{FCBT} ; 45 \%$ PPT). All but $5 \%$ of the final data gathering occurred 18 to 54 months after treatment ( $96 \%$ FCBT; 94\% PPT). The five cases with 3-12-month interviews all reported violence from at least one source and were not prioritized for further follow-up. Most interviews occurred between 18-23 months posttreatment (56\%). The distribution of interviews in 6month segments over the 54-month period was nearly identical between the two conditions. The average length of follow-up for FCBT was 26.0 months $(S D=11.2)$ and for PPT was 24.6 months $(S D=9.4)$, a nonsignificant difference $(t=.70, p=.48)$. For those with interviews at 2 or more years posttreatment, the average follow-up periods again did not differ between the conditions (FCBT: $M=36.0$ months, $S D=10.0$; PPT: $M=34.7$ months, $S D=7.8 ; t=.45, p=.65$ ).

\section{Procedures}

Intake Procedures. Although most of the men were referred by the criminal justice system, all men were required to call the program for an appointment. They normally attended four to six individual intake sessions. In addition to obtaining a comprehensive history of past help seeking, substance abuse, suicide potential, childhood violence, relationship violence and other areas, these sessions included attempts to increase the man's motivation for change, decrease his minimizing about abusive behavior, and develop a control plan. When appropriate, the partner was invited to rehearse a "time-out" procedure (Sonkin, 1989) at the end of the assessment phase. Only a small percentage of the men were screened out because their violence was directed only at nonintimates or because the intake worker decided they could not benefit from group treatment due to severe psychopathology, developmental disabilities, or complete denial of problems. The men also completed a series 
of self-administered questionnaires on attitudes, behavior, and affect (described below). Because the groups were close-ended, some of the men had to wait 2 to 8 weeks to join a treatment group. While waiting, they attended an orientation group every other week for 2 hours each.

Random Assignment. Once a man was determined eligible for treatment, the intake worker explained the experiment to him and he was given an informed consent form to read. Clients were given the option of participating in the experiment or completing a regular course of treatment. The regular treatment consisted of 12 sessions of feminist-cognitive-behavioral group treatment followed by 20 sessions of a mutual support group. Twentytwo men chose the regular condition. The remaining 213 men who were eligible and agreed to participate in the experiment were randomly assigned to one of the two treatments. Five other men were included in the analysis who were assigned to groups based on other criteria. For example, one of the men placed in the PPT groups already had assertiveness training; two other men, both voluntary referrals, had a strong preference for one type of treatment. Supplementary data analyses excluded these five men.

Although the men were to be assigned simultaneously to each condition from the list of eligible men, two of the nine assignments were not simultaneous. One of the PPT groups had too few members to be viable. The group was stopped and then started 3 months later with additional members who were also randomly assigned to that condition. One FCBT group had to be composed only of men with health insurance because the only leader available to start a group was an outside contractor the agency could not otherwise afford. The noninsured men on this waiting list were placed in an FCBT group a month later. Thus the men were still assigned to the proper condition. These problems with randomization should not pose a major threat to validity (e.g., history) because multiple groups of both conditions occurred over a 3-year period.

Of the 218 men assigned to groups, $178(82 \%)$ attended the first group session, 91 in the FCBT condition and 87 in the PPT condition.

Treatments. Both types of treatments used close-ended groups of 20 weekly sessions lasting 2.5 hours each. The FCBT condition followed a highly structured format. Agendas and homework assignments were included in each session (agendas are available on request from the author). Each session included a didactic section on communication and cognitive skills, relaxation/desensitization training, consciousness raising about sex roles and violence against women, and behavioral or cognitive rehearsal. It included the major ingredients of other FCBT models (e.g., Edleson \& Tolman, 1992; Stordeur \& Stilles, 1989).

The PPT did not use agendas but instead followed several phases over the 20 weeks: building trust and a sense of safety; uncovering the childhood traumas and reconnecting with traumatic childhood events; mutual support and awareness of hurt and fear; building awareness of alienation from self and others; transferring lessons about reactions to abuse to current relationships and dealing with termination. Although the group was much less structured than the FCBT condition, it was more structured than most psychotherapy groups. This model is described in detail elsewhere (Browne, Saunders, \& Staecker, in press). Several handouts were used from Gil's (1983) and Whitfield's (1987) work on recovery from childabuse and neglect.

Treatment Integrity. A potential problem with an experiment's internal validity is the misapplication of methods by the leaders. Audiotape recordings were made of each group session to aid in the assessment of treatment validity. These tapes were also used by group supervisors for supervisory purposes. The author created 58 codes in four areas: leader methods, group content, time focus of discussions (e.g., childhood, past month, here and 
now), and relationship focus of discussions (e.g., parents, partner, other group members). The final list of code categories $(n=25)$ was based on ratings by the two primary supervisors regarding the relative importance and predicted time that would be spent on their respective approaches. Graduate students with no investment in the outcome of the treatments were trained to code the tapes. Four 8-minute audio segments were coded from the beginning, middle, and end of each session. A total of 76 hours from each condition was coded, or $17 \%$ of total group time. Each audio segment was reviewed twice for the occurrence of each code. No attempt was made to measure the duration of each behavior but only whether it occurred or not. Three-and-a-half-hours of the tapes (2.1\% total tape time) were coded by two raters. Interrater reliability using percent agreement was adequate (70\%-81\%), except for two areas, leader lecturing and self-disclosure, which were below $40 \%$.

The frequencies of each category by treatment condition are shown in Table 2. Relaxation training and work on coping thoughts occurred almost exclusively in FCBT, as expected. Building emotional awareness, "becoming aware of feelings", on the other hand, occurred at about equal rates. The focus on emotional safety occurred much more often in PPT than in FCBT and the focus on childhood loss and abuse occurred almost solely in the PPT groups. Behaviors characteristic of the FCBT condition, leader and member role-playing, did not occur in the PPT condition. Advise-giving from both leaders and members showed some overlap as expected, yet occurred more than twice as often in the FCBT groups. The same was true for leader lecturing. Self-disclosure also overlapped, yet occurred twice as often in PPT groups, as expected. The PPT focused three times as often on the men's parents and nearly three times as much on group members or leaders. Thus, the treatment delivery appeared to be consistent with the two theoretical frameworks. These findings are consistent with a study of cognitive-behavioral and psychodynamic processes (Jones \& Pulos, 1993 ) in which the cognitive-behavioral techniques emphasized didactic methods, discussion of cognitions, and explicit advice; psychodynamic techniques emphasized memories or reconstructions of childhood, linking feelings to past situations and discussion of the therapy relationship.

Treatment Completion. Completion for this study was defined, as it was by program policy, as attendance at 16 out of 20 sessions. Leader judgments about success, regardless of treatment length, were also taken into account and used in supplementary analyses.

Group Leaders. All of the primary group leaders had extensive experience conducting treatment groups of male offenders. They were clinical social workers or psychologists. All hut one group had a coleader. Coleaders were either other social workers or psychologists,

TABLE 1. Source of Recidivism Reports

\begin{tabular}{lrr}
\hline & FCBT & PPT \\
\hline Woman, man, and arrest re- & $42 \%$ & $38 \%$ \\
$\quad$ Cords & & \\
Woman and arrest & $29 \%$ & $25 \%$ \\
Woman and man & $5 \%$ & $6 \%$ \\
Man and arrest & $11 \%$ & $11 \%$ \\
Woman oniy & $8 \%$ & $4 \%$ \\
Arest only & $5 \%$ & $14 \%$ \\
Man only & $0 \%$ & $1 \%$ \\
Vo report & $0 \%$ & $1 \%$ \\
\hline$\chi^{2}=6.1, p=.53$ & &
\end{tabular}


or master's degree social work interns who had observed at least one series of group sessions. The first two of the PPT groups also had peer group coleaders. We discontinued their use because they had completed the FCBT program and that was their primary orientation for helping the men. An analysis of session tapes with and without these leaders revealed no significant differences in leader methods or the focus of group discussions. Client ratings of helpfulness and support from postgroup questionnaires seemed to favor the professionally led groups, but statistical tests could not be conducted due to small samples.

Of the nine FCBT groups there were seven male-female cotherapy teams, one male-male team, and one male-led group. Of the nine PPT groups, there were seven male-female teams and two male-male teams. Each treatment condition had an African American male leader and the rest of the leaders were Euro-American. None of the leaders in either condition crossed over to lead the other condition. However, one worker originally trained to conduct FCBT groups became a PPT group leader at the start of the experiment. Leaders were chosen partly for their preference for each theoretical orientation.

The supervisor of the FCBT groups had a master's degree in social work and 7 years experience working with men who batter. Three clinicians helped supervise the PPT groups. Each one had more than 5 years experience treating male offenders (assaulters or sex offenders). One was a clinical psychologist and two were clinical social workers. None of them had supervised groups for men who batter because this treatment model had never been used before in this community. The primary supervisor and developer of the model had extensive individual and group experience treating male sex offenders.

\section{Community Context}

The groups met at an established domestic violence program within a nonprofit family service agency. The program participated in a county-wide plan to coordinate victim and offender services with the response of the criminal justice system. The major law enforcement jurisdictions had pro-arrest policies and the prosecutor had a first offenders' program and a victim support program. Probation officers and first offender program staff were trained in the field of domestic violence. As described earlier, $59 \%$ of the men were referred by the courts, $17 \%$ more were under deferred prosecution, and most of the remainder were from social service agencies.

\section{Design}

The study was conducted as a randomized field experiment. As with many such experiments, conditions often become nonequivalent due to attrition during and after the treatment phase (Cook \& Campbell, 1979). Therefore, checks were made on the equivalency of the treatment completers from the two conditions on many behavioral, attitude, and demographic variables.

\section{Equivalency of Conditions}

Despite treatment attrition rates of $38 \%$ for the FCBT condition and $24 \%$ for PPT, the random assignment was apparently not compromised. There were no significant differences between the groups on pretreatment measures of personality, attitudes, depression, anger, partner reports of violence, or number of arrests described below. There were also no differences in age, years of education, income, years in the relationship, use of prior treatment, or mandatory referral. The FCBT condition had more Euro-American clients $191 \%$ 
vs. $77 \%$ ) (chi-square $=8.3 ; p=.04$ ), and tended to have more divorced ( $44 \%$ vs. $29 \%$ ) but fewer separated ( $7 \%$ vs. $13 \%$ ) clients.

Despite the near equivalence of the groups, there were differential predictors of attrition. Younger, less educated men, who had not been victims of child abuse tended to drop out of the FCBT condition. Voluntarily referred men who had witnessed parental violence were more likely to drop from the PPT condition (Chang \& Saunders, 1993).

\section{Recidivism Measures}

Recidivism was primarily measured by the women's reports and was supplemented by men's reports and arrest records.

Women's and Men's Reports of Violence. An expanded version of the Conflict Tactics Scale (CTS) (Straus \& Gelles, 1990) was used for pre-, post- and follow-up reports from the men and women. Items were added on nonviolent threats, using a car recklessly, and sexual abuse (Saunders, 1992). The version contained 12 psychological abuse items and 14 physical abuse items. A short version, offered to women who did not want to complete the long version, condensed the items on abuse to three items and asked for absolute frequencies. The items were: "(a) verbally or emotionally attack you, including insulting, swearing, threatening to leave you, saying you couldn't see certain people; sulking, damaging property, or similar behavior; (b) physical force against you, including threatening to hit you or throw something at you; pushing, carrying, restraining, or grabbing; slapping you; driving recklessly to frighten you; throwing an object at you; kicking you or hitting you with a fist; throwing you bodily; physically forcing sex on you; hitting or trying to hit you with something; (c) beat you up (multiple blows), choke you, make threats with a weapon, or used a weapon against you." Marital status, periods of separation, and how disagreements were handled were also included on the questionnaire. Inquiries about the desire for service for the woman or her children were also made. The focus of this report is on the occurrence of any of the physically abusive behaviors after treatment. The primary source of information was the partner reports 18 to 54 months after treatment. Reports from the men and from official arrest records were used when the women's reports were not available or if the men's reports or the arrest records revealed any violence when the women reported none.

The men were mailed questionnaires containing the expanded CTS 12 months after treatment. Just over half of them returned the questionnaire (FCBT; 58\%; PPT: 54\%). The report of only one man was used exclusively (no partner or arrest report). He was in a PPT group and reported no violence. In two cases the men's reports proved very useful in detecting recidivism because they reported violence and there were no partner reports and the arrest record showed no arrests.

Arrest Records. Pretreatment and posttreatment arrest records of most of the men were obtained from the state's criminal justice computer (FCBT: $87 \%$; PPT: $89 \%$ ). The posttreatment time period ranged from 2.0 to 4.6 years. Arrests were placed in categories: property, financial, person, criminal justice system, weapons, traffic, nontraffic substance abuse, and "other." The focus in this study is on crimes against persons. Most of these were listed as "domestic battery," others were simply labeled "battery." Early in the experiment the state law did not have a specific domestic battery statute, but in some cases it seemed likely the "battery" was often directed at a partner because of the combination of offenses, for example, "concealed weapon, battery, disorderly conduct, attempted sexual assault" in one case, and "false imprisonment, restraining order violation, endangering safety with 
weapon" in another. A case of "resisting and obstructing an officer" was also counted as recidivism.

The arrest records were useful because in 19 cases of arrests against persons the woman's report was not available, she had no contact with her partner, or she reported no violence.

TABLE 2. Treatment Integrity: Frequency of Behaviors Over 76 Hours of Audio Recording

\begin{tabular}{|c|c|c|}
\hline & $\begin{array}{c}\text { FCBT } \\
\text { Feminist-Cognitive- } \\
\text { Behavioral } \\
\end{array}$ & $\begin{array}{c}\text { PPT } \\
\text { Process- } \\
\text { Psychodynamic }\end{array}$ \\
\hline \multicolumn{3}{|l|}{ Content: } \\
\hline Progressive relaxation & 54 & 8 \\
\hline $\begin{array}{l}\text { Using coping thoughts (pos. beliefs about } \\
\text { one-self-attributes, abilities, behavior, etc.) }\end{array}$ & 63 & 3 \\
\hline $\begin{array}{l}\text { Definitions of verbal and physical abuse } \\
\text { (including marital rape) }\end{array}$ & 16 & 15 \\
\hline Becoming aware of feelings & 39 & 36 \\
\hline $\begin{array}{l}\text { Childhood losses and rejections (includes } \\
\text { psychological abuse and being child of } \\
\text { alconolic) }\end{array}$ & 0 & 62 \\
\hline $\begin{array}{l}\text { Childhood experience with violence (seeing } \\
\text { ajuse or being abused) }\end{array}$ & 5 & 38 \\
\hline Emotional safety in group & 7 & 50 \\
\hline \multicolumn{3}{|l|}{$x^{2}=200.3, p<.0001$} \\
\hline \multicolumn{3}{|l|}{ Methods: } \\
\hline $\begin{array}{l}\text { Leader role-play (modeling: at least } 2 \text { people in } \\
\text { verbal exchange) }\end{array}$ & 26 & 0 \\
\hline Member role-play (rehearsal) & 83 & 1 \\
\hline $\begin{array}{l}\text { Advise (giving suggestions \& directions by } \\
\text { member or leader) }\end{array}$ & 240 & 128 \\
\hline $\begin{array}{l}\text { Lecture (provide information abolit skills, } \\
\text { concepts \& problems) }\end{array}$ & 172 & 45 \\
\hline Self-disclosure (by leader or member) & 95 & 215 \\
\hline \multicolumn{3}{|l|}{$x^{2}=220.91, p<.0001$} \\
\hline \multicolumn{3}{|l|}{ Time focus of discussions: } \\
\hline Distant past ( 0 to 18 years $)$ & 19 & 101 \\
\hline Near past ( 18 yrs to $1 \mathrm{mo}$ ago $)$ & 170 & 28.3 \\
\hline Most recent (past month) & 405 & 411 \\
\hline Here \& now (evenis in group) & 145 & 164 \\
\hline Near future (next month) & 91 & 105 \\
\hline Distant future (over 1 month) & 59 & 64 \\
\hline \multicolumn{3}{|l|}{$x^{2}=59.1, p<.0001$} \\
\hline \multicolumn{3}{|l|}{ Relationship focus of discussions } \\
\hline Intimate partner & 299 & 307 \\
\hline Man's parents & 34 & 101 \\
\hline Co-worker & 41 & 21 \\
\hline Group member or leader & 69 & 198 \\
\hline Self & 351 & 443 \\
\hline
\end{tabular}

$\chi^{2}=73.5, p<.0001$ 
In some of these cases, he was probably violent toward a new partner. Although the men's report and the arrest report were congruent in 10 cases, in two cases of arrest the men reported no violence. A limitation of this measure is that in nine cases in which no arrest was reported, we could not verify if either partner was living in the state.

The response rate of the women during the follow-up period was $79 \%$. If one adds the remaining cases in which either an arrest occurred $(n=8)$ or the man reported violence $(n=1)$, the "conservative" response rate is $85 \%$. If one includes the presence of all three reports (given the problems noted above), the "liberal" response rate is $99 \%$. The source of report (woman, man or arrest) or the various combinations did not differ significantly between conditions. This information appears in Table 1.

\section{Women's Measures}

Fear. The women were asked the extent to which they feared physical abuse from their partners before treatment and at each follow-up point: "In general, I fear physical abuse from my partner: not at all, a little bit, a moderate amount, a great deal." A second item substituted "psychological abuse" for physical abuse.

Conflict Resolution. A single item was used to assess general conflict style before and after treatment: "When disagreements arise, do they generally result in: man giving in, woman giving in, neither giving in, agreement by mutual give and take."

General Changes. The women were asked two open-ended questions during the follow-up: (1) "During or since the group, have you noticed any positive changes in your partner?" ; (2) During or since the group, have you noticed any negative changes in your partner." In most cases more than one change was noted. Cases were classified as: positive only, negative only, or a mixture of the two. The frequencies of positive and negative changes for each case were also recorded.

\section{Men's Measures.}

A packet of self-report questionnaires were administered to the men during the intake phase and again between the last group session and an exit interview with a counselor. This report will focus on the use of these measures in determining the success of randomization and trait-treatment interactions.

Millon Clinical Multiaxial Inventory (MCMI-1). The MCMI was used to assess the personality traits and disorders of the men (Millon, 1983). It contains 175 items that measure eight personality and character disorders (Axis II), three chronic and dysfunctional personality disorders (Axis II) and nine circumscribed or transient clinical syndromes. The MCMI shows good internal-structural validation and external validity with many other measures. It contains corrections for psychological defensiveness, self-deprecation, and denial tendencies. The dependent and antisocial-aggressive scales were the most relevant in this study. All 20 scales were factor-analyzed to reduce the data. The five resulting factors were used to further test the hypotheses. They were: (1) dependent/somataform; (2) drugabuse/alcohol abuse/ narcissistic/ hypomanic/ antisocial; (3) avoidant/borderline/anxious/depressed; (4) paranoid; and (5) compulsive/passive-aggressive. The traits with the highest loadings are placed first in the above lists.

Relationship Satisfaction. A short, 11-item version of a marital satisfaction scale was used and relabelled the "Relationship Inventory" (Roach, Frazier, \& Bowden, 1981). The highest loading items were chosen from the original scale. The original scale shows very 
high concurrent validity and internal reliability, and nonsignificant correlations with social desirability.

Beliefs About Woman Abuse. The Inventory of Beliefs about Wife Beating (Saunders, Lynch, Grayson, \& Linz, 1987) was used to measure the men's beliefs and attitudes. It contains 31 items in five subscales: wife beating is justified, wives gain from the abuse, help should be given, the offender is responsible, and the offender should be punished. Evidence exists for its concurrent and known groups' validity using various populations. The first three subscales can be combined into a scale of sympathy toward battered women that has very good internal reliability.

Self-Esteem. The Rosenberg Self-Esteem Scale was used. This is a 10-item measure of self-esteem that shows good construct and concurrent validity and high internal reliability (Fleming \& Courtney, 1984). The version used here had a 4-point response format from "strongly disagree" to "strongly agree."

General Hostility. The Buss-Durkee Hostility Inventory consists of 66 items in seven subscales (Buss \& Durkee, 1957): assault, indirect hostility, irritability, negativism, resentment, suspicion, and verbal hostility. It appears to have a two-factor structure, one emphasizing resentment and suspicion and the other aggressive behaviors. Almost all of the subscales appear to discriminate well between violent and nonviolent populations. The internal reliability of some of the subscales is not very high.

Traditional Views of Women's Roles. The 15-item version of the Attitudes Toward Women Scale was used (Spence \& Helmreich, 1978). The response format is from "strongly agree" to "strongly disagree." Its internal reliability with college men is .89 (alpha). It demonstrates construct validity through its ability to differentiate males and females and older and younger persons; its ability to predict profeminist reactions to competent women; and its correlation with acceptance of gender stereotypes (Spence \& Helmreich, 1978).

Democratic Decision Making. A short version of the Power Decision Index (Blood \& Wolfe, 1960) was used to measure the extent to which the man or the woman has the final say in five areas of marital decision making. The greatest weight is given if the couple shares decision making and the least is given if either one is dominant. A modified version of the scale, used in the first national study of family violence (Straus, Gelles, \& Steinmetz, 1980) was used here.

Level of Conflict. This construct was measured with the Marital Conflict Index . It was used in the first national study of family violence (Straus, Gelles, \& Steinmetz, 1980). Respondents are asked to rate five areas in the relationship (managing money, affection and sexual relations, household chores, social activities, and children) on the frequency of agreement in the past year, from "always" to "never."

Anger Toward Partner. A spouse-specific version of the Novaco Anger Index (Novaco, 1975) was used. It uses a 5-point scale to indicate reactions to situations, from "very little anger" to "very much anger." The index showed positive changes following cognitive and relaxation treatments. Twenty of the interpersonal items from the original 80 -item scale were changed to "partner." In previous studies with men who batter the internal reliability coefficient was .89 (Saunders \& Hanusa, 1986).

Jealousy. A measure of romantic jealousy developed by White (1977) was used. It contains 6 items. It has high internal reliability and correlates as expected with dependency on the relationship.

Depression. The Beck Depression Inventory was used (Beck, 1961). It is a 21 -item measure covering somatic complaints, guilt, pessimism and indecisiveness. The split half reli- 
ability is .86 . Criterion validity has been demonstrated based on the inventory's correlations with ratings of patients.

Adjustments for Social Desirability. The attitude and affect measures were adjusted for the tendency of the men to answer in a socially desirably manner. A 10-item version of the Marlowe-Crowne Scale with a 7-point Likert scale (Greenwald \& Satow, 1970) was used. It has an internal reliability coefficient equivalent to the original scale.

\section{RESULTS}

\section{Expectation Effects}

Because the experiment was conducted within a program that had used only one of the methods for about 10 years, the intake workers or others in the agency could have conveyed positive expectancies about the FCBT group that might lead to placebo effects. Analysis of evaluations completed by the men after the first four group sessions showed that positive expectations of change were high for both types of treatment. The men responded to the item "As a result of this program, I expect to improve my ability to prevent my psychological and physical abuse of others." Both groups averaged between moderate and high expectations with the FCBT group somewhat higher on a five point scale ( $M=4.5 \mathrm{vs.} 4.3$, $t=2.94, p=.003$ ). Perceived helpfulness of each session did not differ between the conditions on a 6-point scale, ranging from "not helpful at all" to "very helpful."

\section{Main Effects}

Table 3 shows the recidivism rates for the two treatment conditions. Those who completed 16 or more of the 20 sessions are included, plus two other men whom the leaders considered successful. The first comparison is based only on the women's reports, regardless of whether they had contact with their partners. The next comparison is more stringent since it excludes women with no partner contact. Finally, an even more stringent comparison is shown with the addition of the men's reports and the arrest records. Regardless of the comparison made, the recidivism rates are almost identical between the conditions and did not differ significantly. The results were similar under more stringent criteria: the removal of cases not randomly assigned $(n=5)$, the removal of cases if they completed 16 sessions instead of $17(n=9)$, and the removal of cases the leaders judged unsuccessful $(n=8)$.

TABLE 3. Recidivism Rates for Physical Abuse After Treatment

\begin{tabular}{lcccc}
\hline & $\begin{array}{c}\text { Feminist-Cognitive } \\
\text {-Behavioral (FCBT) }\end{array}$ & $\begin{array}{c}\text { Process-Psychodynamic } \\
\text { (PPT) }\end{array}$ & $\chi^{2}$ & $p$ \\
\hline $\begin{array}{l}\text { Women's reports (3-54 } \\
\text { mos. after treatment) }\end{array}$ & $30.9 \%(17 / 55)$ & $28.8 \%(15 / 52)$ & .001 & .98 \\
$\begin{array}{l}\text { Women's reports only } \\
\text { if contact with partner }\end{array}$ & $34.0 \%(17 / 50)$ & $33.3 \%(15 / 45)$ & .024 & .87 \\
$\begin{array}{l}\text { Women's reports } \\
\quad \text { partner contact and/or }\end{array}$ & $45.9 \%(28 / 61)$ & $48.5 \%(33 / 68)$ & .001 & .98 \\
$\begin{array}{l}\text { arrest record and/or } \\
\text { man's report) }\end{array}$ & $26.8 \%(15 / 56)$ & & & \\
$\begin{array}{l}\text { Arrests: Any crime } \\
\text { Arrests: Crimes against persons }\end{array}$ & $23.2 \%(13 / 56)$ & $28.1 \%(18 / 64)$ & .001 & .94 \\
\hline
\end{tabular}


TABLE 4. Nonviolent Outcomes Reported by the Women (At Last Posttreatment Interview)

\begin{tabular}{lccr}
\hline & $\begin{array}{c}\text { Cognitive-Behavioral } \\
\text { (FCBT) }\end{array}$ & $\begin{array}{c}\text { Process- } \\
\text { Psychodynamic (PPT) }\end{array}$ & \\
\hline General changes during & $n=45$ & 41 & $\chi^{2}$ \\
and after treatment & & & $0.8 n s$ \\
$\quad$ positive \& negative & $56 \%$ & $59 \%$ & \\
positive only & $31 \%$ & $34 \%$ & $5.5 n s$ \\
negative only & $13 \%$ & $7 \%$ & \\
& $n=44$ & 44 & \\
Fear of physical abuse & & & \\
not at all & $54 \%$ & $52 \%$ & $3.3 n s$ \\
a little bit & $39 \%$ & $32 \%$ & \\
a moderate amount & $7 \%$ & $5 \%$ & \\
a great deal & $0 \%$ & $11 \%$ & \\
& $n=45$ & 40 & $3.4 \mathrm{~ns}$ \\
Fear of psychological abuse & & & \\
not at all & $42 \%$ & $50 \%$ & \\
a little bit & $36 \%$ & $28 \%$ & \\
a moderate amount & $15 \%$ & $7 \%$ & \\
a great deal & $7 \%$ & $15 \%$ & \\
& $n=41$ & 38 & \\
Result of disagreements & & $47 \%$ & \\
mutual agreement & $46 \%$ & $32 \%$ & \\
neither give in & $32 \%$ & $0 \%$ & \\
woman give in & $15 \%$ & & \\
man give in & $7 \%$ & & \\
\hline
\end{tabular}

Table 3 also shows the rates of arrest for all crimes and crimes against persons. Again there were no significant differences. The average number of arrests in these categories of crime also did not differ significantly between the conditions (All crimes: FCBT $M=$ $.50, S D=1.4$, PPT $M=.72, S D=1.4, t=-.85$; Crimes against persons: FCBT $M=.09$, $S D=.4$, PPT M $=.05, S D=.2, t=.67$ ). Psychological abuse rates did not differ between the two groups.

Table 4 shows other outcomes reported by the women. In response to the open-ended questions about changes in the men during and after treatment, just over half of the women reported that they observed both positive and negative changes. About a third observed only positive changes. Thirteen percent of the FCBT men's partners and 7\% of the PPT men's partners reported only negative changes. These differences were not significant. The average number of positive and negative changes per case also did not differ significantly between the conditions (positive: FCBT $M=1.7, S D=.8$; PPT $M=1.8, S D=.9, t=1.36$; negative: FCBT $M=1.7, S D=.8$; PPT $M=1.5, S D=.8, t=1.12$ ).

The average level of fear for both groups was between "a little bit" and "a moderate amount" prior to treatment and fell to "a little bit" by the last point in the follow-up. After treatment, almost half of the women, regardless their partners' treatment, reported that disagreements were solved by "mutual give and take." Many reported that neither gave in (32\% in both conditions). The differences between conditions were not significant. 
Note that for all of these comparisons, information was available from about $50 \%-70 \%$ of the women, primarily because most of these measures were not available with the short questionnaire.

\section{Interaction Effects.}

The interaction analysis sought to determine if men with certain traits had lower recidivism rates depending on which treatment they received. The Dependent and Antisocial-Aggressive subscales of the MCMI were used to test the interaction hypotheses in three forms: as continuous variables, as diagnoses (BR 75), and as part of factor scores with other MCMI traits. Forty percent of the men showed the presence of an antisocial personality since they had base rate scores of 75 on this subscale; $33 \%$ of the men had BR scores above 75 on the dependent subscale. These rates may be inflated because there is evidence that the MCMI1 tends to overdiagnose. The dependent variable was recidivism of any form of physical abuse among treatment completers ( 16 or more sessions) based on reports from the woman, and/or her partner, and/or the state's crime data base. Ten of the 136 men had missing MCMI scales.

A separate regression analysis was conducted for each trait. The MCMI scale score or diagnosis (above $75 \mathrm{BR}$ ) and the treatment condition were entered first into logistic regressions, followed by the MCMI-by-treatment type interaction term. A significant increase in $\mathrm{R}$-squared indicates a significant interaction effect. The two traits were also combined with closely related traits through factor analysis and factor scores were used in the equations. Dependent personality was closely linked with somataform disorder. Antisocial personality was closely linked with drug/alcohol abuse potential and histrionic personality.

Table 5 shows the results of the interaction analysis. A diagnosis of dependent personality interacted significantly with treatment. As predicted, those with this disorder had lower recidivism rates for the PPT treatment and higher recidivism for the FCBT treatment. The use of scale scores or factor scores did not produce significant interactions.

A diagnosis of antisocial personality did not interact significantly with treatment approach, although the relationship was in the predicted direction. However, the scale score and factor score (antisocial with substance abuse potential and histrionic scale scores) did interact significantly with treatment type. Those scoring higher on antisocial personality had lower recidivism rates in FCBT groups and higher rates in the PPT groups.

TABLE 5. Interaction of Offender Traits with Treatment Models in Predicting Recidivism: Percentage of Variance Increase from Interaction Term

\begin{tabular}{|c|c|c|}
\hline \multicolumn{3}{|c|}{ Recidivism: Any Report $(n=126)$} \\
\hline & $\mathrm{R}^{2}$ incr. & $F$ \\
\hline Dependent Personality Diagnosis & $2.9 \%$ & $3.62^{*}$ \\
\hline Dependent Personality Score & $1.2 \%$ & 1.43 \\
\hline Dependent/Somataform Factor Score & $0.8 \%$ & 1.03 \\
\hline Antisocial Personality Diagnosis & $1.6 \%$ & 1.95 \\
\hline Antisocial Personality Score & $3.2 \%$ & $3.94 *$ \\
\hline Drug/Alc//Histrionic/Antisocial Factor Score & $3.8 \%$ & $4.95^{*}$ \\
\hline Hypomanic Score & $4.8 \%$ & $6.21^{*}$ \\
\hline Relationship Satisfaction Score & $3.7 \%$ & $4.44^{*}$ \\
\hline
\end{tabular}


Figure 1. Interaction of offender traits and type of treatment: Percent with violence recidivism by any report
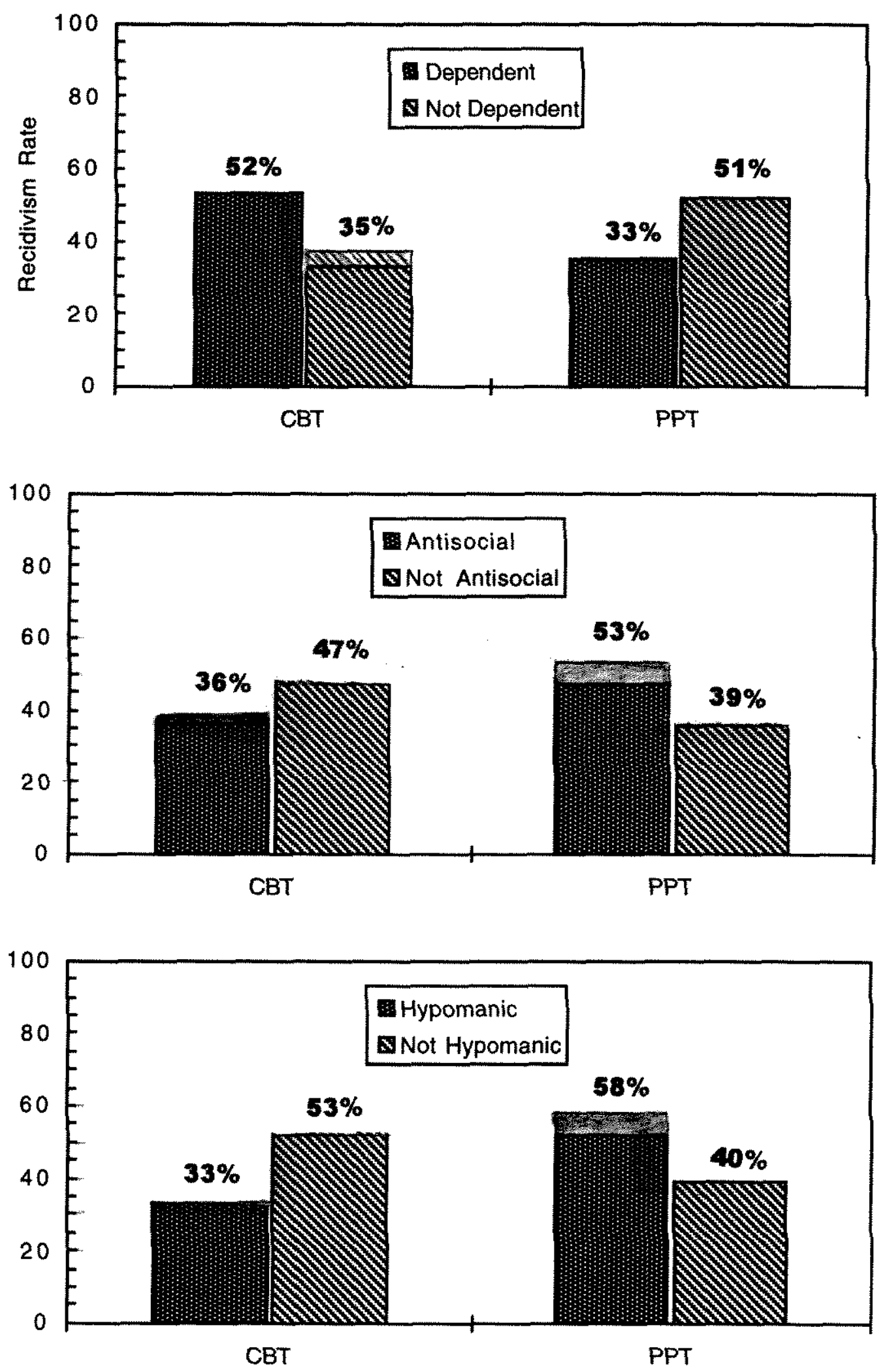

Note. CBT=cognitive-behavioral treatment; PPT=process-psychodynamic treatment 
Figure 1 illustrates some of the interactions. Those with a dependent diagnosis had a recidivism rate of $52 \%$ if in an FCBT group and only $33 \%$ in a PPT group. The opposite was true if they did not have this diagnosis, with a recidivism rate of $35 \%$ in an FCBT group and $51 \%$ in a PPT group. Those with an antisocial diagnosis had a recidivism rate of $36 \%$ if in a FCBT group and 53\% if in a PPT group; without an antisocial diagnosis, they had a $47 \%$ recidivism rate in the FCBT groups and $39 \%$ in the PPT groups.

Two other interactions were significant. Those scoring higher on the hypomanic scale of the MCMI tended to have lower recidivism rates if they were in FCBT groups but higher ones if they were in PPT groups. Those scoring high on this scale tend to be labile, restless, distractible, impulsive, and irritable. If a man had a high BR score (over 65) on this scale, his recidivism rate in the FCBT condition was only $33 \%$ and it was $58 \%$ in the PPT condition; conversely, a non-hypomanic score led to a 53\% recidivism rate in FCBT and a $40 \%$ recidivism rate in PPT (Fig 1). Finally, those who were more satisfied with their relationships prior to treatment had lower recidivism rates if they were in the FCBT groups. They had higher recidivism rates if they were in a PPT group.

\section{Correlates of Personality Traits}

Childhood traumas (witnessing or being abused), attitudes, mood states (jealousy, anger, depression), and criminal behavior did not interact significantly with the treatments in predicting outcome. However, many of these variables were significantly related to personality traits in expected directions. There is space here to report only some of the findings. Witnessing parental abuse was significantly related to violence against strangers $(r$ $=.22, p<.01)$ and parents $(r=.24, p<.01)$. Violence against strangers, in turn, was positively related to antisocial personality $(r=.21, p<.05)$ and negatively related to dependent personality $(r=-.22, p<.01)$. Severe child abuse was related to violence against parents $(r=.20, p<.05)$, which in turn was related to antisocial personality $(r=.25, p<.01)$. Attitudes and mood states were more strongly related to a third personality constellation of avoidant, borderline, and depressive traits. Thus, while childhood traumas appear to affect adult behavior and personality, they do not seem to have a direct link to differential outcomes.

\section{DISCUSSION}

This study of the relative efficacy of two treatments for men who batter demonstrates that it is possible to conduct long-term follow-up with a fairly high response rate and to apply treatments in accord with the theoretical orientations espoused by each treatment model. Similar to many studies in other fields that compare "behavioral" and "insight" approaches, there were no differences found between the cognitive-behavioral and processpsychodynamic conditions. Multiple measures and multiple sources of reports were used, relying primarily on the reports of the men's partners 18 to 54 months after treatment. There were no differences reported between treatments in rates of physical abuse or the women's fear levels, general perceptions of change in their partners, or ways of resolving conflicts. These results contrast somewhat with those of Edleson and Syers (1991, 1992) that seemed to favor more structured approaches. The accumulated findings from many studies will obviously be needed to answer questions about the optimal level of structure. 
The recidivism rates in this study are in the middle of the range of rates from other abuser outcome studies (Tolman \& Edleson, 1995). However, they rose considerably when adding arrest records and show the utility of obtaining these reports. In some cases a woman had not been in contact with her partner, yet an arrest for a crime against a person appearing on his record was most likely from his abuse of another woman.

Because of treatment attrition, the initial randomization to treatments was compromised. The comparison of treatment completers on many behavioral, attitude, demographic, and personality variables on pretreatment measures indicated equivalence. However, it is impossible to know if a key variable went untested. As in many field experiments, the experimental design becomes a quasiexperimental one and only statistical means can be used to try to assure pretreatment equivalence.

The treatment attrition rates were comparable to those of other studies. However, the rate was somewhat lower in the process-psychodynamic treatment (PPT). These results appear to be consistent with those of Stosny (1994) who used a video tape and group discussion early in treatment to arouse the men's compassion to their own traumatic childhoods. Treatment involvement and retention were higher in the "compassion" model. Many programs delay (or never) discuss childhood issues until the final phases of treatment, following accountability, skills training, or other phases. This study suggests that some men may need to work on their childhood traumas early in treatment. The program studied here may have been different than most, however, since considerable work on helping the men increase their accountability for their behavior occurred in individual assessment interviews.

The major finding of this study is that personality styles and disorders interacted with the type of treatment being received. Men with antisocial traits were less likely to be violent after treatment if they attended the feminist-cognitive-behavioral treatment. Men with dependent traits, on the other hand, had better outcomes with the process-psychodynamic treatment. Those with substance abuse potential and hypomania also had lower recidivism in the feminist-cognitive-behavioral condition. The antisocial, substance-abusing offender may need the structure of the FCBT groups. He is more likely to have been severely physically abused in childhood and probably learned to repress most feelings and developed a detached style of relating. The skills-training of the FCBT groups may have matched his action-oriented learning style or his need for structure. The hypomanic offender, sharing the impulsivity of many antisocial offenders, may have benefited from the relaxation training and cognitive restructuring of FCBT groups. The dependent personality probably experienced parental rejection more than direct physical abuse (Dutton, 1994) and developed an anxious attachment style. The unstructured nature of the PPT groups, focusing on group relationships, probably matched the needs of this offender.

Those reporting more satisfying relationships had better outcomes in the FCBT groups. This finding is more difficult to interpret. FCBT may have been more relevant to them because it focused heavily on communication skills and these skills may have been successfully transferred to the home.

There are several important limitations to keep in mind about the findings: (1) A notreatment control group was not used and thus any reports of change cannot be attributed conclusively to the treatments. Other events in the men's lives, such as arrest or the threat of divorce, may produce substantial change. Although unlikely, the brief interventions that occurred during intake and orientation sessions might also account for lack of group differences. (2) Despite multiple reports of recidivism, the findings are probably underestimates. Reliance on the men's 12-month follow-up reports and on arrest reports are quite likely to be underestimates. Some women may also have underreported their abuse out of shame, fear, or repression of traumatic events. Because the research project was based in 
the treatment program, some women may not have trusted the assurances that their reports would be kept from their partners. (3) Some of the measures used with the women were only a single item and have unknown reliability and validity. (4) Despite using experienced group leaders and experienced supervisors, there were no tests of leader competence and thus no assurance the competence levels were equal between the treatments or comparable to other programs. (5) Finally, some of the tests of statistical interaction were posthoc and need to be replicated in future studies.

In spite of these limitations, this study helps to answer some important methodological questions about the ability to conduct posttreatment follow-up evaluations and test treatment integrity. More important, it is the first step in guiding future studies that would a priori match abuser types with specific kinds of treatment in order to improve outcomes. Progress is being made in such matching in the alcoholism field (e.g., Litt, Babor, DelBoca, Kadden \& Cooney, 1992). For practitioners, this study suggests that in developing programs for men who batter, "one size does not fit all." The assumption that all offenders will benefit from highly structured psychoeducational groups that avoid discussion of childhood issues needs to be questioned. Finally, while the results contain signs of hope about treatment effectiveness, a substantial number of men repeated their violence after treatment. More research is needed to identify these treatment failures and to create effective dispositions. These could range from: longer treatment, treatment combined with close probationary supervision or treatment while incarcerated.

\section{REFERENCES}

Adams, D. (1988). Treatment models of men who batter: A profeminist analysis. In K. Yllo \& M. Bograd (Eds.), Feminist perspectives on wife abuse. Newbury Park, CA: Sage.

Andrews, D.A., Zinger, I., Hoge, R.D., Bonta, J., Genreau, P., Cullen, F.T. (1990). Does correctional treatment work? A clinically relevant and psychologically informed metaanalysis. Criminology, 28, 369-404.

Beck, A.T., Ward, C.H., Mendelson, M., Mock, J., \& Erbaugh, J. (1961). An inventory for measuring depression. Archives of General Psychiatry, 4, 53-63.

Blood, R.E., \& Wolfe, D.M. (1960). Husbands and wives. Glencoe,IL: Free Press.

Browne, K., Saunders, D.G., \& Staecker, K.M. (1997). Process-psychodynamic groups for men who batter: Description of a brief treatment model. Families in Society, 78 , 265-271.

Buss, A. H., \& Durkee, A. (1957). An inventory for assessingdifferent kinds of hostility. Journal of Clinical and Consulting Psychology, 21, 343-349.

Chang, H., \& Saunders, D.G. (1993). An analysis of attrition in batterers' counseling. Paper presented at the Ninth Annual Symposium on Empirical Group Work, Ann Arbor, Michigan, May, 1993.

Cook, T.D., \& Campbell, D.T. (1979). Quasi-experimentation: Design and analysis issues in field settings. Boston: Houghton-Mifflin.

Deffenbacher, J.L., McNamara, K., Stark, R.S., \& Sabadell, P.M. (1990). A comparison of cognitive-behavioral and process-oriented group counseling for general anger reduction. Journal of Counseling and Development, 69, 167-172.

Dunford, F. (1992). The measurement of recidivism is cases of spouse assault. Journal of Criminal Law and Criminology, 83, 183-206. 
Dutton, D. (1986). The outcome of court-mandated treatment for wife assault: A quasiexperimental evaluation. Violence and Victims, 1, 163-176.

Dutton, D. (1994). The origin and structure of the abusive personality. Journal of Personality Disorders, 8(3), 181-191.

Dutton, D. (1995). Trauma symptoms and PTSD-Like profiles in perpetrators of intimate abuse. Journal of Traumatic Stress, 8 (2), 299-316.

Dutton, D.G., \& Starzomski, A.J. (1993). Borderline personality in perpetrators of psychological and physical abuse. Violence and Victims, 8 (4), 327-337.

Dutton, D.G., van Ginkel, C., \& Starzomski, C. (1995). The role of shame and guilt in the intergenerational transmission of abusiveness. Violence and Victims, 10, 121-132.

Edleson, J.L. (1984). Working with men who batter. Social Work, 29, 237-242.

Edleson, J.L. \& Syers, M. (1990). The relative effectiveness of group treatment for men who batter. Social Work Research and Abstracts, 26, 10-17.

Edleson, J. L., \& Syers, M. (1991). The effects of group treatment for men who batter: An 18 month follow-up study. Research on Social Work Practice, 1, 227-243.

Edleson, J.L. \& Tolman, R.M. (1992). Intervention for men who batter: An ecological approach. Newbury Park, CA: Sage.

Fleming, \& Courtney, (1984). The dimensionality of self-esteem: II. Hierarchical facet model for revised measurement scales. Journal of Personality and Social Psychology, 46, 404-421.

Ganley, A. L. (1989). Integrating feminist and social learning analyses of aggression. In P. L. Caesar \& L. K. Hamberger (Eds.), Treating men who batter. New York: Springer Publishing Company.

Gil, E. (1983). Outgrowing the pain. New York: Dell.

Greenwald, H.J., \& Satow, Y. (1970). A short social desirability scale. Psychological Reports, $27,131-135$.

Hamberger, L.K., \& Hastings, J.E. (1986). Personality correlates of men who abuse their partners: A cross-validation study. Journal of Family Violence, 1 (4), 323-341.

Hamberger, L. K., \& Hastings, J. E. (1993). Court-mandated treatment of men who assault their partners: Issues, controversies, and outcomes. In N. Z. Hilton (Ed.), Legal responses to domestic violence. Newbury Park, CA: Sage.

Harrell, A. V. (1991). Evaluation of court-ordered treatment for domestic violence. Final report submitted to the State Justice Institute. Washington, DC: The Urban Institute.

Holtzworth-Munroe, A., \& Stuart, G.L. (1994). Typologies of male batterers: Three subtypes and the differences among them. Psychological Bulletin, 116 (3), 476-497.

Hotaling, G. T., \& Sugarman, D. B. (1986). An analysis of risk markers in husband to wife violence: The current state of knowledge. Violence and Victims, 1, 101-124.

Jennings, J. L. (1987). History and issues in the treatment of battering men: A case for unstructured group therapy. Joumal of Family Violence, 2, 193-214.

Jones, E. E., \& Pulos, S. M. (1993). Comparing the process in psychodynamic and cognitive-behavioral therapies. Journal of Consulting and Clinical Psychology, 61, 306316.

Litt, M.D., Babor, T.F., DelBoca, F.K., Kadden, M., \& Cooney, N.L. (1992). Types of alcoholic, II: Application of an empirically derived typology to treatment matching. Archives of General Psychiatry, 49, 609-614.

Millon, T. (1983). Millon Clinical Multiaxial Inventory. Minneapolis, MN: National Computer Systems.

Novaco, R. W. (1975). Anger control. Lexington, MA: Lexington.

O'Leary, K.D. (1988). Physical aggression between spouses: A social learning perspective. In van Hasselt, Morrison, Bellak, \& Hersen (Eds.), Handbook of family violence. New York: Plenum. 
Parker, B., \& Ulrich, Y. (1990). A protocol of safety: Research on abuse of women. Nursing Research, 39, 248-250.

Roach, A.J., Frazier, L.P., \& Bowden, S.R. (1981). The marital satisfaction scale: Development of a measure for intervention research. Journal of Marriage and the Family, 9, 130141.

Rosenfeld, B. D. (1992). Court-ordered treatment of spouse abuse. Clinical Psychology Review, 12, 205-226.

Rumptz, M.H., Sullivan, C.M., Davidson, W.S., \& Basta, J. (1991). An ecological approach to tracking battered women over time. Violence and Victims, 6, 237-244.

Saunders, D.G. (1984). Helping husbands who batter. Social Casework, 65(6), 347-353.

Saunders, D.G. ,\& Azar, S. (1989). Treatment programs for family violence. In L. Ohlin \& M. Tonry (Eds.), Family violence: Crime and justice, a review of research (Vol. II). Chicago, IL: University of Chicago Press.

Saunders, D. G., \& Hanusa, D. R. (1986). Cognitive-behavioral treatment of men who batter: The short-term effect of group therapy. Journal of Family Violence, I(4), 357-372.

Saunders, D. G., Lynch, A. E., Grayson, M., \& Linz, D. (1987). The inventory of beliefs about wife beating. The development and initial validation of a measure of beliefs and attitudes. Violence and Victims, 2, 39-57.

Scher, M., \& Stevens, M. (1987). Men and violence. Joumal of Counseling and Development, $65,351-355$.

Sonkin, D. J. (1989). Learning to live without violence. CA: Volcano Press.

Spence, J.T. \& Helmreich, R.L. (1978). Masculinity and feminity: Their psychological dimensions, correlates, and antecedents. University of Texas, Austin.

Stordeur, R. \& Stilles, R. (1989). Ending men's violence against their partners. Newbury Park, CA: Sage.

Stosny, S. (1994). Shadows of the Heart: A dramatic video for the treatment resistance of spouse abusers. Social Work, 39, 686-694.

Straus, M.A. \& Gelles, R.J. (1990) Physical violence in American families. New Brunswick, NJ: Transaction.

Straus, M. A., Gelles, R. J., \& Steinmetz, S. K. (1980). Behind closed doors: Violence in the American family. New York: Doubleday/Anchor.

Tolman, R. M., \& Bennett, L. W. (1990). A review of research on men who batter. Journal of Interpersonal Violence, 5, 87-118.

Tolman, R. M., \& Edleson, J. L. (1995). Intervention for men who batter: A review of research. In S. Stith \& M. A. Straus (Eds.), Understanding intimate violence. Minneapolis: National Council on Family Relations.

van Hasselt, V.B., Morrison, R.L., Bellack, A.S., \& Hersen, M. (1988). Handbook of family violence. New York: Plenum.

White, G.L. (1977). The social psychology of romantic jealousy. Dissertation Abstracts International, 37(10), 5449-B.

Whitfield, C.L. (1987). Healing the Inner Child. Deerfield Beach, FL: Health Communications.

Yllo, K. (1984). Patriarchy and violence against wives: The impact of structural and normative factors. Journal of International and Comparative Social Welfare, 1, 16-29.

Acknowledgements Funding for this study was provided by the Centers for Disease Control, Grant Award No. R49/CCR 502584-03, "Preventing Injuries from Marital Violence" to Daniel G. Saunders, Principal Investigator; the Research and Development Fund, Department of Psychiatry, University of Wisconsin-Madison, 133-P978; and the Office of the Vice President for Research, 
University of Michigan. The author is grateful to the sponsoring program, Alternatives to Aggression, Family Service, Madison, Wisconsin, and to all those who worked on the project, including the consultants, group leaders, interviewers, and office workers. He is especially grateful to the project coordinators, Patricia Cumbie, Susan Shepanek, Judith Witt, and Randy Magen, and to the group supervisors, Kevin Browne, Darald Hanusa, Dorothy Helman., Kathryn Staecker, and Pauline Thome.

Offprints. Requests for offprints should be directed to Daniel G. Saunders, School of Social Work, University of Michigan, 1065 Frieze Building, Ann Arbor, MI 48109-1285. 